\title{
PD Source Location Utilizing Acoustic TDOA Signals in Power Transformer by Fuzzy Adaptive Particle Swarm Optimization
}

\author{
Kalyan Chakravarthi MEKA, A. V. GIRIDHAR, D. V. S. S. SIVA SARMA \\ Dept. of Electrical Engineering, National Institute of Technology Warangal, TS, 506004, India \\ kalyan.mvr@gmail.com, \{giridhar,dvss\}@nitw.ac.in \\ Submitted February 2, 2018 / Accepted September 18, 2018
}

\begin{abstract}
Partial discharge (PD) source location using acoustic emission (AE) is widely utilized by many transformer manufacturers and power utility engineers in routine and critical situation for optimal operation of the electrical power system as well as further risk management and repair planning. The PD detection is not enough to take solution, so identification of PD source is essential to restore apparatus condition. This work aim is to localize the defect geometrically by means of TDOA (time difference of arrival) signals from the sensors fixed on the power transformer. The solution for PD source location is acquired by making these nonlinear equations as optimization problem. In this technique, the inertia weight is effectively regulated by using 49 and 9 simple IF-THEN fuzzy rules to improve the global optimal solution and impairs the local convergence problem and improves the accuracy in estimating the PD source location. The simulation results reveal that $P D$ location accuracy with minimum of maximum deviation error, absolute error and relative error is better when compared to other constant parameter intelligent methods which were reported in the literature.
\end{abstract}

\section{Keywords}

Acoustic emission, partial discharge, fuzzy adaptive particle swarm optimization, fuzzy rules, source localization

\section{Introduction}

Partial discharges are the initial root cause of insulation degradation in any high voltage power apparatus. Its accurate detection and diagnosis in time is essential otherwise simultaneously the degradation of insulation may happen progressively and discharge level increases drastically. It may lead to a catastrophic failure and results in outage and penalty costs. Therefore, the identification and diagnosis of PD's is prerequisite at inception stage where the unexpected failures and further losses can be diminished [1-3]. PD generates acoustic waves which transmit inside the transformer tank. The acoustic sensors are fixed on the transformer tank's external side to detect the propagation of acoustic signals from the PD source [4-6]. This acoustic method is an indirect method and has distinct merits compared to direct electrical methods. They are noninvasive, easier installation and non-interference. The TDOA (Time Difference of Arrival) method [7], [8] is widely used by many researchers for accurate PD source localization. In this paper, the TDOA method is used for time differences of AE signals from a reference sensor to remaining sensors thus PD source location is detected.

$\mathrm{Lu}$ et al. demonstrated the pattern recognition approach for PD source location in the simulated oil filled transformer tank by partitioning into small modules. The PD source is located with high location error by calculating the minimum distance between the standard and its undetermined pattern vectors of the total tank. Thereby, this approach is inaccurate for the onsite measurement [5]. Markalous et al. [7] utilized pseudo time approach in global position system (GPS) algorithm for PD source localization detected by acoustic sensors but its drawback is sometimes it gives confused solution. Veloso et al. [9], [10] compared the least square (LS) method and genetic algorithm for localization of PD source and it is located accurately with large population size and iterations by genetic method whereas iterative LS method located with inaccurate manner. Tang et al. [11] compared iterative LS method and PSO method for localization of PD source, when compared to LS method, PSO method gives better location results. Kundu et al. [12] illustrated a non-iterative method for localization of PD source and its demerit is, it also yields two different solutions similar to GPS algorithm and in that only one solution is true. The obtained location error is also high, Kill et al. has demonstrated 2-D co-ordinate system using three acoustic sensors and located the PD source with $1 \%$ error in laboratory prototype model [13]. Kuo et al. [14] used combined PSO-ANN (artificial neural network) for PD defects recognition under noisy and noiseless conditions with $80 \%$ success rate. Bozcar et al. [15] used artificial neural network for recognition of PD defects in paper oil insulation damaged by aging action. H. L. Liu et al. [16] applied sequential quadratic program- 
ming-genetic algorithm for PD source location with more population size. H. L. Liu et al. [17] employed quantum genetic algorithm for PD source location with more population and iterations.

Z. Hasirci et al. [18] applied PSO algorithm to optimize frequency dependent model parameters for different bus bar distribution systems (630, 1250 and 2000 A) and these bus bars functioning as a power line communication at $3-148.5 \mathrm{kHz}$ band were analyzed for frequency and phase shift keying modulations to distinct network alignments. C. Han et al. [19] applied Feedback PSO (FPSO) algorithm to minimize the peak side lobe on both digital position shift method and digital position shift with optimal amplitude methods, but the optimized results of both methods shown inferior with other methods reported in the literature particularly steering direction near to end fire direction. E. Tugcu et al. [20] used PSO method for blind verification of channel matched filter (CMF) coefficients and shown better performance in terms of bit error rate and mean square error of frequency selective channels with other conventional blind training methods. L. Song et al. [21] implemented box particle cardinalized probability hypothesis density filter for tracking multiple targets and shown superior performance: particularly detection probability decreases and more clutter appears compared to box particle cardinalized probability hypothesis density (BP$\mathrm{CPHD})$ filter and sequential monte Carlo cardinalized probability hypothesis density (SMC-CPHD) filter. F. Gunes et al. [22] proposed honey bee mating optimization (HBMO) in designing an ultra-wide band low noise amplifier for delivering maximum power and required noise. This HBMO method shown better results than other methods published in the literature. O. Cakir et al. [23] investigated the performance of PSO with time difference of arrival average (TDOAA) method for emitter location and the location results shown better position accuracy than other classical methods.

K. N. Abdulrani et al. [24] proposed the modified cuckoo search (MCS) algorithm for synthesizing linear array geometry symmetrically with low level of side lobe and its performance is slightly better than PSO and GA methods. A. Akubulut et al. [25] demonstrated the channel state transition probabilities as unknown by secondary users with PSO method and the obtained results shown better even in transient conditions. Zhonghun Ma et al. [26] applied PSO method on two different wide band medium gain antenna arrays design and instructed to employ fitness function based on realized gain. V. Sedenka et al. [27] implemented multi objective PSO and non-dominated sorting genetic algorithms (NSGA-II) on a cavity microwave resonator synthesis and the multi objective PSO method obtained better results than NSGA-II method. J. Lacik et al. [28] demonstrated the multi criterion optimization for bow tie antenna using PSO with time domain multi objective function for designing broadband antennas. V. Raptis et al. [29] investigated the different parameters such as antenna height, additional variable capacitance and varactor voltage for a planar inverted $\mathrm{F}$ antenna. These antennas are equipped in modern telecommunication systems to operate in different frequency bands. J. Kracek et al. [30] evaluated maximal power delivered to appliance by reference levels of electric and magnetic field strengths fulfilment with the help of two simple examples. P. Kadlec et al. [31] compared least square and sliding correlator methods for pilot symbol embedded channel estimation. Simulation results shown by least square estimation are best for precise CIR findings even in terms of computational demands. S. K. Chronopoulos et al. [32] used PCCC technique in turbo coded OFDM system under different noise scenarios.

Many authors used iterative and metaheuristic methods [33] in their domain of research. It has been confirmed that no algorithm can perform best for different research problems till now. The conventional methods i.e. iterative and non-iterative methods take more computation and time to produce the better results and the iterative method depends on correct starting guess values. The optimization algorithms also take large number of population and iterations for getting better results. Hence, hybridization of optimization method with other methods may enhance the search space to balance the overall exploration and exploitation ability, convergence speed, and ability of searching global optimum, less computation time and better results when compared to conventional and optimization methods. PSO is one of the most widely used evolutionary algorithms in hybrid methods due to its simplicity. Some works reported in the literature [34] which have been controlling either inertia weight or acceleration parameters of PSO methods targeted to reduce the trapping probability of local minimum. In view of above, the FAPSO has been adopted in the present work for improving the accuracy of PD source localization.

\section{Formulation of PD Source Problem}

The PD source and the sensor positions placement on the transformer tank is shown in Fig. 1. The $\mathrm{P}(x, y, z)$ is the estimated PD source and the sensors positions are $\mathrm{S}_{1}\left(x_{\mathrm{a}}, y_{\mathrm{a}}, z_{\mathrm{a}}\right)$, $\mathrm{S}_{2}\left(x_{\mathrm{b}}, y_{\mathrm{b}}, z_{\mathrm{b}}\right), \mathrm{S}_{3}\left(x_{\mathrm{c}}, y_{\mathrm{c}}, z_{\mathrm{c}}\right)$ and so on $\mathrm{S}_{\mathrm{n}}\left(x_{\mathrm{n}}, y_{\mathrm{n}}, z_{\mathrm{n}}\right)$. The sensor $\mathrm{S}_{1}$ is considered as the reference sensor to activate the further sensors.

\subsection{Objective Function}

The aim of this localization of PD source is to minimize the location error.

$$
\begin{gathered}
g=\sqrt{\left(x-x_{\mathrm{a}}\right)^{2}+\left(y-y_{\mathrm{a}}\right)^{2}+\left(z-z_{\mathrm{a}}\right)^{2}}, \\
p=\sqrt{\left(x-x_{\mathrm{b}}\right)^{2}+\left(y-y_{\mathrm{b}}\right)^{2}+\left(z-z_{\mathrm{b}}\right)^{2}}-g-v_{\mathrm{a}} \tau_{21}, \\
q=\sqrt{\left(x-x_{\mathrm{c}}\right)^{2}+\left(y-y_{\mathrm{c}}\right)^{2}+\left(z-z_{\mathrm{c}}\right)^{2}}-g-v_{\mathrm{a}} \tau_{31},
\end{gathered}
$$




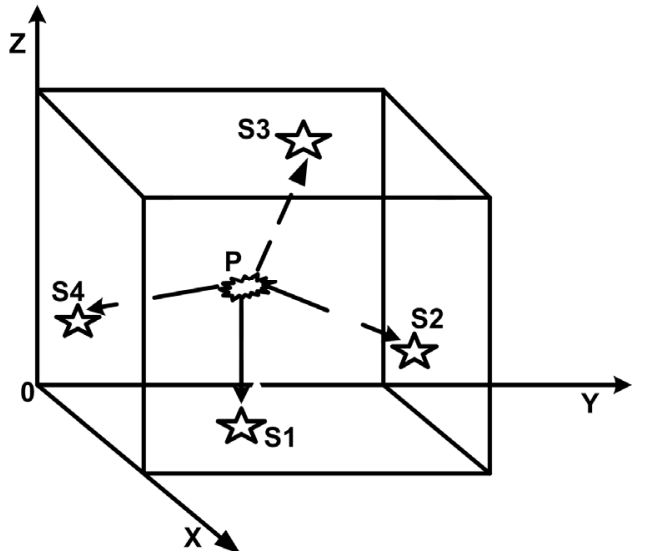

Fig. 1. PD Source and sensors placement on the transformer tank.

$$
\begin{aligned}
r= & \sqrt{\left(x-x_{\mathrm{d}}\right)^{2}+\left(y-y_{\mathrm{d}}\right)^{2}+\left(z-z_{\mathrm{d}}\right)^{2}}-g-v_{\mathrm{a}} \tau_{41}, \\
s= & \sqrt{\left(x-x_{\mathrm{e}}\right)^{2}+\left(y-y_{\mathrm{e}}\right)^{2}+\left(z-z_{\mathrm{e}}\right)^{2}}-g-v_{\mathrm{a}} \tau_{51}, \\
& \min \left\{\mathrm{D}_{\mathrm{f}}\left(x, y, z, v_{\mathrm{a}}\right)\right\}=p^{2}+q^{2}+r^{2}+s^{2} .
\end{aligned}
$$

In (1), $(x, y, z)$ is the PD source position, $\mathrm{S}_{1}\left(x_{\mathrm{a}}, y_{\mathrm{a}}, z_{\mathrm{a}}\right)$ is the first sensor fixed position on the transformer tank. In (2), $(x, y, z)$ is the PD source position, $\mathrm{S}_{2}\left(x_{\mathrm{b}}, y_{\mathrm{b}}, z_{\mathrm{b}}\right)$ is the second sensor fixed position on the transformer tank, $\tau_{21}$ is the time difference between sensor 2 and sensor 1. In (3), $(x, y, z)$ is the PD source position, $\mathrm{S}_{3}\left(x_{\mathrm{c}}, y_{\mathrm{c}}, z_{\mathrm{c}}\right)$ is the third sensor fixed position on the transformer tank, $\tau_{31}$ is the time difference between sensor 3 and sensor 1 . In (4), $(x, y, z)$ is the PD source position, $\mathrm{S}_{4}\left(x_{\mathrm{d}}, y_{\mathrm{d}}, z_{\mathrm{d}}\right)$ is the fourth sensor fixed position on the transformer tank, $\tau_{41}$ is the time difference between sensor 4 and sensor 1 . In (5), $(x, y, z)$ is the PD source position, $\mathrm{S}_{5}\left(x_{\mathrm{e}}, y_{\mathrm{e}}, z_{\mathrm{e}}\right)$ is the fifth sensor fixed position on the transformer tank, $\tau_{51}$ is the time difference between sensor 5 and sensor 1 . In (6), $\min \left\{\mathrm{D}_{\mathrm{f}}\left(x, y, z, v_{\mathrm{a}}\right)\right\}$ is minimization of the objective function with constraints length ( $\min <x<\max ) \mathrm{mm}$, width $(\min <y<\max ) \mathrm{mm}$, height $(\min <z<\max ) \mathrm{mm}$ and acoustic velocity $\left(1200<v_{\mathrm{a}}<1500\right) \mathrm{m} / \mathrm{s}$ of the transformer tank considered.

\section{Proposed Method}

PSO is based on the evolution of birds flocking closely to swarming intelligence and it was proposed by Kennedy and Eberhart in 1995. This approach includes in such a way that at each iteration, upgrading the velocity and position of every particle, each particle moves in the direction of its $\mathrm{P}_{\text {best }}$ position based on memory and $\mathrm{g}_{\text {best }}$ position based on information of (7), (8) respectively.

$$
\begin{gathered}
\mathbf{v}_{k}^{t+1}=w \mathbf{v}_{k}^{t}+c_{1} \operatorname{rand}_{1}\left(\mathbf{p}_{\text {best }}-\mathbf{x}_{k}^{t}\right)+c_{2} \operatorname{rand}_{2}\left(\mathbf{g}_{\text {best }}-\mathbf{x}_{k}^{t}\right), \\
\mathbf{x}_{k}^{t+1}=\mathbf{x}_{k}^{t}+\mathbf{v}_{k}^{t+1} .
\end{gathered}
$$

In (7), w is the inertia weight, $v_{k}^{t}$ is the current particle velocity, $\mathbf{v}_{k}^{t+1}$ is the new velocity vector, $t$ is the iteration count, $c_{1}$ and $c_{2}$ are learning parameters, rand $_{1}$ and rand $_{2}$ are random numbers, $\mathbf{p}_{\text {best }}$ and $\mathbf{g}_{\text {best }}$ are local best solution and global best solution, $\mathbf{x}_{k}{ }^{t}$ is the current particle solution. In (8), $\mathbf{x}_{k}^{t+1}$ is the new position vector, $\mathbf{x}_{k}^{t}$ is the current particle position vector, $\mathbf{v}_{k}^{t+1}$ is the new velocity vector.

Normally, PSO velocity contains three segments, i.e. the momentum segment, the cognitive learning segment and the social learning segment. The PSO performance is improved by the equilibrium among these segments, i.e., which controls the local and global searching abilities. In PSO, the inertia weight is utilized to balance the global and local searching abilities. A huge inertia weight accelerates a global search while a little inertia weight accelerates a local search. The searching abilities will be dynamically improved by tuning the inertia weight effectively.

The searching procedure of PSO is a non-linear and difficult approach. The sequential or straight line declining inertia weight process has a linear progression capability from global to local search and has not shown the effective searching process for obtaining the optimum solution. Hence, the inertia weight should be changed nonlinearly and dynamically for improvement in the performance and equilibrium between global and local searching abilities. Conveniently with some ideas of PSO searching procedure is assembled and linguistic relation of the searching procedure for localization of PD source is attainable. This idea and linguistic relation formulate a fuzzy interference system for adjustment of PSO inertia weight dynamically to solve the localization of PD source problem. The remaining part of this paper explains modelling a fuzzy system and adapting inertia weight effectively for localization of PD source problem. The simple IF-THEN fuzzy rules in Tab. 1 and (9)-(12) are utilized for the proposed methods, i.e., FAPSO-I consists of 49 fuzzy rules listed in Tab. 1 and FAPSO consists of 9 fuzzy rules.

In Figs. 2-4, triangular membership functions are considered and they are represented by seven linguistic elements (NL, NM, NS, Z, PS, PM and PH) for negative large, negative medium, negative small, zero, positive small, positive medium and positive high respectively are used for fuzzification of every input and output. The fuzzy logic block diagram with two inputs and one output is shown in Fig. 5. In this fuzzy logic system, fuzzification block converts crisp value to fuzzy value, fuzzy interference engine has the capability of simulating human decision making based on fuzzy rules of inference in fuzzy logic and the defuzzifier block converts fuzzy value to crisp value using centroid method.

\subsection{Formulation of Fuzzy System}

A fuzzy rule base design is developed using inertia weight of the PSO algorithm to get better accuracy in the PD location results. The fuzzy logic system contains three 


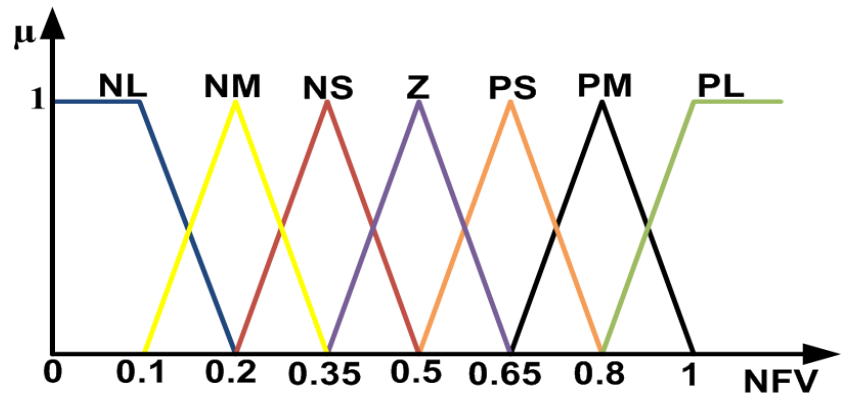

Fig. 2. Representation of Triangular Membership functions for Normalized Fitness Input.

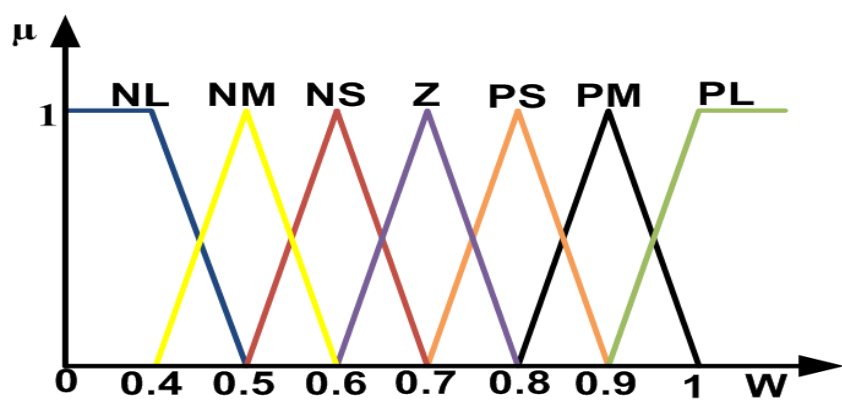

Fig. 3. Representation of Triangular Membership functions for Inertia Weight Input.

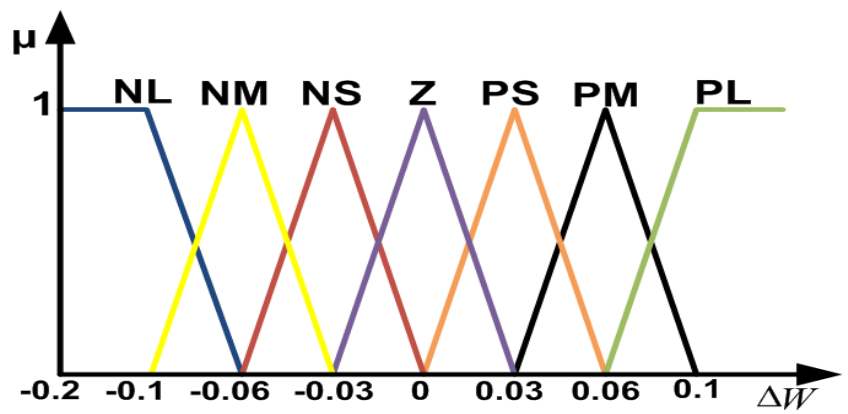

Fig. 4. Representation of Triangular Membership functions for Change in Inertia Weight Output.

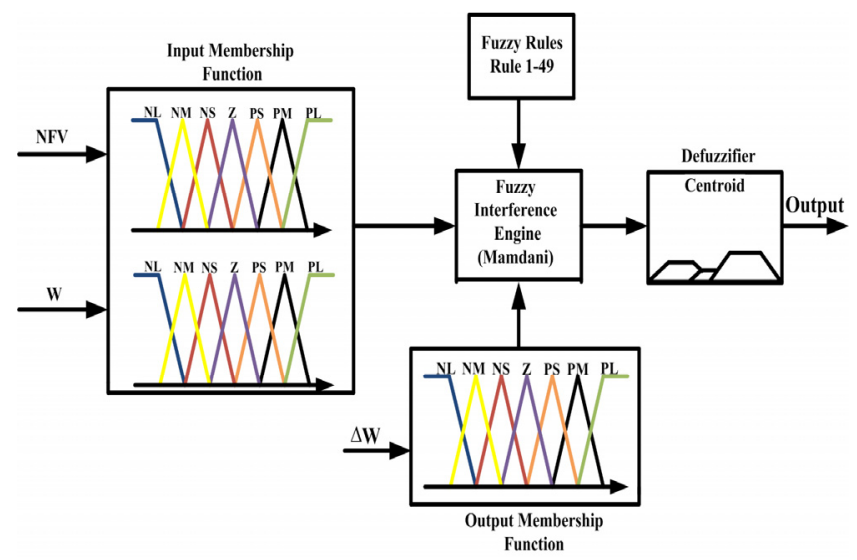

Fig. 5. Fuzzy Logic System with two inputs and one output.

main segments, i.e., fuzzification, inference system and defuzzification. To find a good inertia weight in the fuzzy domain, inputs of the fuzzy system are normalized fitness and the inertia weight while the output is inertia weight. In order to establish a crisp mathematical model for the adaptive PSO, it is very hard to actively modify the inertia weight parameters. Therefore, easily understanding IFTHEN rules are appropriate to compute the some portion of inertia weight modification in the fuzzy adaptive PSO procedure to locate the PD source.

Normalized fitness: The current solution fitness is very crucial to guess the inertia weight for the correct choice of the velocity. In general, normalized fitness lies in between 0 and 1 and it is given by

$$
\text { Fit } t_{\text {normalise }}=\frac{f_{\text {gbest }}-f_{\text {gbestold }}}{10-f_{\text {gbestold }}} \text {. }
$$

In (9), $f_{\text {gbest }}$ is the global best fitness value for considered iterations and $f_{\text {gbestold }}$ is the old global best fitness value for the first iteration from (8).

Inertia Weight: Its value lies in between 0.4 and 1 for this problem.

Change in Inertia Weight: In this paper, its value is placed in between -0.1 and 0.1 .

IF-THEN rules and defuzzification: For FAPSO, forty nine rules are constructed using seven linguistic values for every input element. The simple IF-THEN rules are shown in Tab. 1. The arithmetic product operator is used as conjunction for the input and output elements in the formulation of individual rules. For every rule, output element will be scaled based on degree of membership (DOM).

\subsection{Fuzzy Adaptive PSO Formulation:}

The velocity and position computations for the proposed fuzzy adaptive PSO are as follows

$$
w_{k}^{t+1}=w_{k}^{t}+\Delta w_{k}^{t}
$$

$$
\begin{gathered}
\mathbf{v}_{k}^{t+1}=w_{k}^{t+1} \mathbf{v}_{k}^{t}+c_{1} \operatorname{rand}_{1}\left(\mathbf{p}_{\text {best }}-\mathbf{x}_{k}^{t}\right)+c_{2} \operatorname{rand}_{2}\left(\mathbf{g}_{\text {best }}-\mathbf{x}_{k}^{t}\right), \\
\mathbf{x}_{k}^{t+1}=\mathbf{x}_{k}^{t}+\mathbf{v}_{k}^{t+1}
\end{gathered}
$$

In (10), $w_{k}^{t+1}$ is the new adaptive weight, $t$ is the iteration count, $w_{k}^{t}$ is the $k^{\text {th }}$ particle weight, $\Delta w_{k}^{t}$ is the change in weight value. In (11), $\mathbf{v}_{k}^{t+1}$ is the new velocity vector, $v_{k}^{t}$ is the $k^{\text {th }}$ particle velocity, $t$ is the iteration count, $w_{k}^{t+1}$ is the adaptive inertia weight, $c_{1}$ and $c_{2}$ are learning parameters, rand $_{1}$ and rand $_{2}$ are random numbers, $p_{\text {best }}$ and $g_{\text {best }}$ are local best solution and global best solution, $\mathbf{x}_{k}{ }^{t}$ is the current particle solution. In (12), $\mathbf{x}_{k}^{t+1}$ is the new position vector and other terms are the same as in (11).

\section{Results and Discussions}

The simulations are performed on the same experiment measurements data but the population size is reduced from 50 to 20 and total iterations are reduced from 200 to 100. The calculated location of PD source results obtained 


\begin{tabular}{|c|c|c|c|}
\hline \multirow{2}{*}{$\begin{array}{c}\text { Rule } \\
\text { Number }\end{array}$} & \multicolumn{2}{|c|}{ Antecedent } & \multirow{2}{*}{$\frac{\text { Consequent }}{\Delta \mathbf{W}}$} \\
\hline & NFV & $\mathbf{W}$ & \\
\hline 1 & NL & NL & $\overline{\mathrm{NL}}$ \\
\hline 2 & NM & NL & $\mathrm{NL}$ \\
\hline 3 & $\mathrm{NS}$ & NL & $\mathrm{NL}$ \\
\hline 4 & $\mathrm{Z}$ & NL & NL \\
\hline 5 & PS & NL & $\overline{\mathrm{NM}}$ \\
\hline 6 & PM & NL & $\mathrm{NS}$ \\
\hline 7 & PL & NL & $\bar{Z}$ \\
\hline 8 & NL & NM & NL \\
\hline 9 & NM & NM & $\mathrm{NL}$ \\
\hline 10 & NS & NM & NL \\
\hline 11 & $\bar{Z}$ & NM & $\overline{\mathrm{NM}}$ \\
\hline 12 & PS & NM & NS \\
\hline 13 & PM & NM & $\mathrm{Z}$ \\
\hline 14 & PL & NM & PS \\
\hline 15 & NL & NS & $\overline{N L}$ \\
\hline 16 & NM & NS & $\overline{\mathrm{NL}}$ \\
\hline 17 & NS & NS & NM \\
\hline 18 & $\mathrm{Z}$ & NS & NS \\
\hline 19 & PS & NS & $\bar{Z}$ \\
\hline 20 & PM & NS & PS \\
\hline 21 & $\begin{array}{l}\mathrm{PL} \\
\end{array}$ & NS & PM \\
\hline 22 & NL & $\begin{array}{l}Z \\
\end{array}$ & NL \\
\hline 23 & NM & $Z$ & $\mathrm{NM}$ \\
\hline 24 & NS & $\bar{Z}$ & $\mathrm{NS}$ \\
\hline 25 & $Z$ & $\mathrm{Z}$ & $\mathrm{Z}$ \\
\hline 26 & PS & $\mathrm{Z}$ & PS \\
\hline 27 & PM & $\mathrm{Z}$ & PM \\
\hline 28 & PL & $Z$ & PL \\
\hline 29 & NL & PS & $\overline{\mathrm{NM}}$ \\
\hline 30 & NM & PS & NS \\
\hline 31 & NS & PS & $\bar{Z}$ \\
\hline 32 & $\mathrm{Z}$ & PS & PS \\
\hline 33 & PS & PS & PM \\
\hline 34 & PM & PS & $\begin{array}{l}\mathrm{PL} \\
\end{array}$ \\
\hline 35 & PL & PS & $\overline{\mathrm{PL}}$ \\
\hline 36 & NL & PM & NS \\
\hline 37 & NM & PM & $\mathrm{Z}$ \\
\hline 38 & NS & PM & PS \\
\hline 39 & $\mathrm{Z}$ & PM & PM \\
\hline 40 & PS & PM & $\mathrm{PL}$ \\
\hline 41 & PM & PM & $\overline{\mathrm{PL}}$ \\
\hline 42 & PL & PM & PL \\
\hline 43 & NL & $\mathrm{PL}$ & NL \\
\hline 44 & NM & PL & NM \\
\hline 45 & NS & PL & NS \\
\hline 46 & $\mathrm{Z}$ & PL & $\mathrm{Z}$ \\
\hline 47 & PS & PL & PS \\
\hline 48 & PM & $\mathrm{PL}$ & PM \\
\hline 49 & PL & PL & $\begin{array}{l}\mathrm{PL} \\
\end{array}$ \\
\hline
\end{tabular}

Tab. 1. Fuzzy rules for FAPSO-I.

from 20 iterations in the case study. The simulation parameters of the FAPSO-I and FAPSO for PD source location are swarm population is 20, maximum number of iterations is 100 , learning parameters $c_{1}, c_{2}=2$. Location Error in millimetres can be determined by

$$
\sqrt{\left(\mathrm{x}_{\text {actual }}-\mathrm{x}_{\text {calculated }}\right)^{2}+\left(\mathrm{y}_{\text {actual }}-\mathrm{y}_{\text {calculated }}\right)^{2}+\left(\mathrm{z}_{\text {actual }}-\mathrm{z}_{\text {calculated }}\right)^{2}} \text {. }
$$

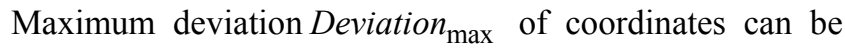
estimated by

$$
\text { Deviation }_{\max }=\max \left\{\begin{array}{l}
x_{\text {actual }}-x_{\text {calculated }} \\
y_{\text {actual }}-y_{\text {calculated }} \\
z_{\text {actual }}-z_{\text {calculated }}
\end{array}\right\} .
$$

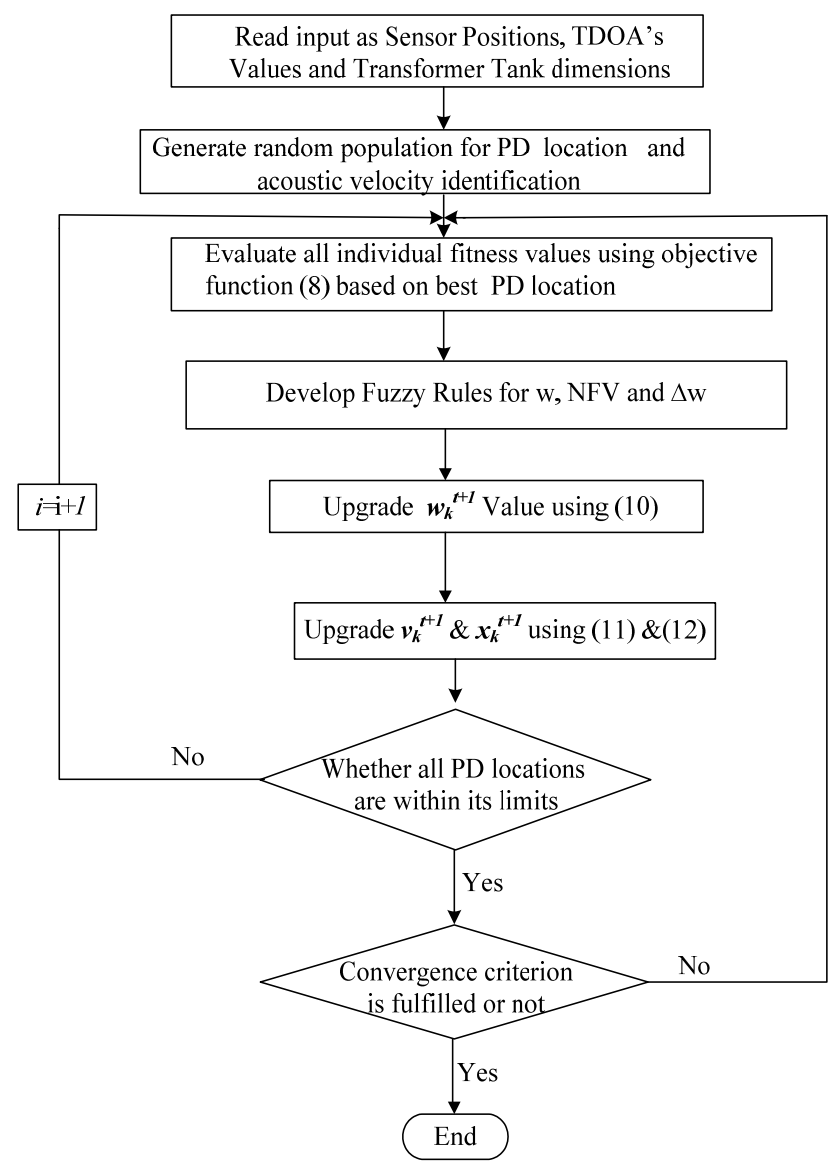

Fig. 6. Flow chart of FAPSO and FAPSO-I.

where $x_{\text {actual }}, y_{\text {actual }}, z_{\text {actual }}$ is actual PD location and $x_{\text {calculated, }}$ $y_{\text {calculated }}, z_{\text {calculated }}$ is calculated PD location. The Relative Error can be calculated as (Location Error/TankDiagonal) $\times 100$. Tank Diagonal is $\sqrt{x^{2}+y^{2}+z^{2}}$ where $x$ is the length, $y$ is the width, $z$ is the height of the transformer tank in mm.

\subsection{Case Study of Field Data}

The onsite measurement data is collected from [15], [16] which is measured data on power transformer. In (5), five sensors are used in this case study and Table 2 shows the calculated PD location results. The actual PD coordinates are $\left(X_{\mathrm{PD}}, Y_{\mathrm{PD}}, Z_{\mathrm{PD}}\right)=(4500,2600,3700) \mathrm{mm}$. The final results for different algorithms are the best values of the PD location solutions. Table 2 shows the comparison of final PD source solution obtained with the proposed FAPSO-I and FAPSO algorithms with five algorithms in the existing literature. Table 3 shows the comparison of error analysis with the proposed FAPSO-I and FAPSO algorithms with different methods in the reported literature with reference to the tank diagonal $\left(D_{\text {tank }}=7071.07 \mathrm{~mm}\right)$.

The location of PD source results with the proposed methods and available literature are shown in Tab. 2. The proposed methods FAPSO-I and FAPSO locate the PD source within 58.47 and $62.83 \mathrm{~mm}$ of PD source location error and maximum deviation error of 45.1 and $58.3 \mathrm{~mm}$ in Tab 3. From Tab. 3, it is observed that the maximum devi- 
ation error and relative error of the proposed algorithm is insignificant when compared to other methods in the available literature. The convergence characteristics comparison of FAPSO-I and FAPSO algorithm for this case study is shown in Fig. 7, the FAPSO-I algorithm takes less number of iterations to locate accurate $\mathrm{PD}$ source compared to FAPSO algorithm.

The proposed FAPSO-I gives minimum location error, maximum deviation error and relative error with less

\begin{tabular}{|c|c|c|c|c|}
\hline Methods & $\begin{array}{c}\text { Co- } \\
\text { ordinates }\end{array}$ & $\mathbf{X}(\mathbf{m m})$ & $\mathbf{Y}(\mathbf{m m})$ & $\mathbf{Z}(\mathbf{m m})$ \\
\hline \multicolumn{2}{|c|}{ Actual Coordinates } & 4500 & 2600 & 3700.0 \\
\hline \multicolumn{2}{|l|}{ FAPSO-I } & 4465.9 & 2554.9 & 3714.9 \\
\hline \multicolumn{2}{|l|}{ FAPSO } & 4485.6 & 2541.7 & 3718.5 \\
\hline \multicolumn{2}{|l|}{ QGA [16] } & 4394.77 & 2475.98 & 3656.17 \\
\hline \multicolumn{2}{|l|}{ GA $[16]$} & 4223.76 & 2391.73 & 3503.04 \\
\hline \multicolumn{2}{|l|}{ SA } & 4387.78 & 2470.01 & 3666.64 \\
\hline \multicolumn{2}{|l|}{ PSO [15] } & 4383.32 & 2470.53 & 3649.16 \\
\hline \multicolumn{2}{|l|}{ LPSO [15] } & 4382.14 & 2469.99 & 3648.11 \\
\hline
\end{tabular}

Tab. 2. Comparison of field PD location results with proposed methods and different methods in available literature.

\begin{tabular}{|c|c|c|c|c|}
\hline Methods & Errors & $\begin{array}{c}\text { Location } \\
\text { Error }(\mathbf{m m})\end{array}$ & $\begin{array}{c}\text { Maximum } \\
\text { Deviation } \\
\text { Error (mm) }\end{array}$ & $\begin{array}{c}\text { Relative } \\
\text { Error } \\
\mathbf{( \% E )}\end{array}$ \\
\hline \multicolumn{2}{|c|}{ FAPSO - I } & 58.47 & 45.1 & 0.83 \\
\hline FAPSO & 62.83 & 58.3 & 0.89 \\
\hline QGA [16] & 124.02 & 168.45 & 1.75 \\
\hline GA [16] & 276.24 & 398.10 & 3.91 \\
\hline SA [15] & 129.99 & 174.94 & 1.84 \\
\hline PSO [15] & 129.47 & 181.55 & 1.83 \\
\hline LPSO [15] & 130.01 & 182.99 & 1.84 \\
\hline
\end{tabular}

Tab. 3. Comparison of field data error analysis of different methods in literature with the proposed methods.

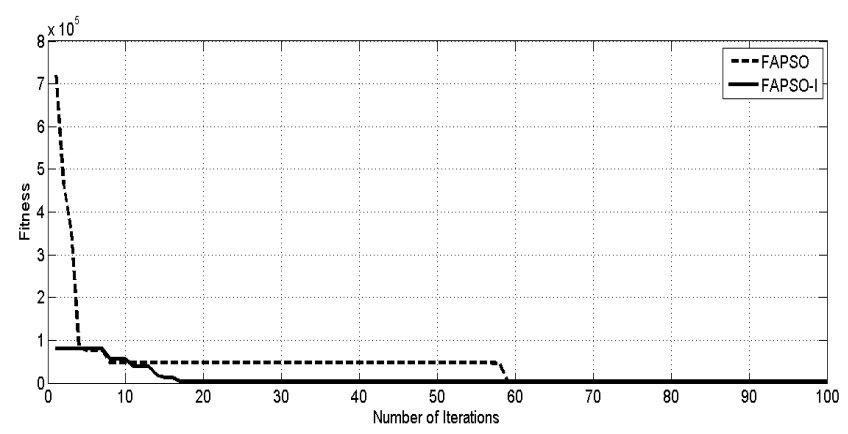

Fig. 7. Comparison of convergence characteristics of FAPSO-I and FAPSO algorithm of case study.

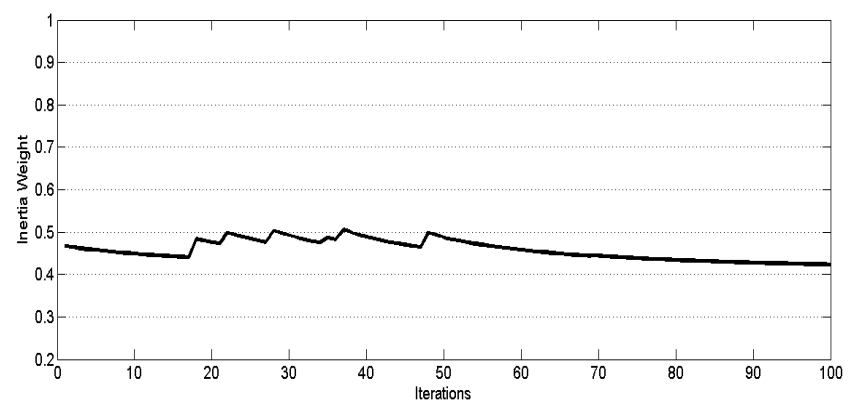

Fig. 8. Adjustment of inertia weight by FAPSO-I. execution time when compared to other methods. Figure 8 shows the inertia weight variation for a randomly chosen length and the convergence characteristic of the fuzzy adaptive PSO. The straight segment of the curve specifies that there is no change in the weight tuning of PSO.

\subsection{Case Study Laboratory Data}

The laboratory experimental related data is taken from [10] for PD source localization. The actual PD source position was fixed for four different time differences measured by moving the pin-plate electrode for four times. The sensors are located at $S_{1}(800,820,0), S_{2}(1000,420,346)$, $\mathrm{S}_{3}(345,782,800)$ and $\mathrm{S}_{4}(0,468,386)$. Table 4 shows the comparison of PD location and its error results with the proposed methods and different methods published in literature obtained for each set up (i.e. for each PD source and its TDOA measurements).

It is observed from Tab. 4 that the location error of PD source is lower for accurate time delay measurements from the sensors and higher for inaccurate time delay measurements from the sensors and it is also observed that the proposed algorithm gives minimum PD location error compared with PSO and LS methods. It is observed from Tab. 5 that the PD source maximum deviation error is significantly lower for accurate time delay measurements from the sensors and higher for inaccurate time delay measurements from the sensors. It can also be found that PD source location by the proposed method is much better when compared with the available literature results. The relative error obtained by the proposed method is also lower when compared to other methods as shown in Tab. 5 .

It is also revealed that the PD source location by the proposed method is much better for both laboratory and field experimental data when compared with the available literature results. Thereby, the proposed method has shown its capability to localize the PD source with good accuracy.

\section{Conclusion}

In this paper, fuzzy adaptive PSO (FAPSO-I \& FAPSO) has proposed to obtain search capabilities of the particles. The PSO result greatly influences on inertia weight $(w)$ and learning factors $\left(c_{1} \& c_{2}\right)$ and it may trap into local premature convergence problem. To prevail over this problem, inertia weight is tuned dynamically by using conditional IF-THEN statements in order to obtain the global best solution. From the output results, it is noticed that the proposed FAPSO-I method converge to global optimum solution owing to inertia weight fuzzification. To analyze the fuzzy adaptive PSO correctly, the good choice of inertia weight and learning factors results in such a way that all the particles tend to move in the direction of global optimum location compared to PSO. Thus, the proposed FAPSO-I takes very less time owing to inertia weight has been tuned dynamically using fuzzy rules. This FAPSO-I 


\begin{tabular}{|c|c|c|c|c|c|c|c|c|c|}
\hline $\begin{array}{l}\text { PD source } \\
\text { position } \\
\text { No }\end{array}$ & $\begin{array}{l}\text { Actual PD } \\
\text { coordinates } \\
(\mathrm{mm})\end{array}$ & $\begin{array}{l}\text { PD location } \\
\text { results of LS } \\
(\mathrm{mm})[10]\end{array}$ & $\begin{array}{l}\text { PD location } \\
\text { results of PSO } \\
(\mathrm{mm})[10]\end{array}$ & $\begin{array}{l}\text { PD location } \\
\text { results of } \\
\text { FAPSO }(\mathrm{mm})\end{array}$ & $\begin{array}{l}\text { PD location } \\
\text { results of } \\
\text { FAPSO-I (mm) }\end{array}$ & $\begin{array}{l}\text { Location } \\
\text { error of LS } \\
(\mathrm{mm})[10]\end{array}$ & $\begin{array}{l}\text { Location } \\
\text { error of } \\
\text { PSO (mm) } \\
{[10]} \\
\end{array}$ & $\begin{array}{l}\begin{array}{l}\text { Location } \\
\text { error of }\end{array} \\
\text { FAPSO } \\
(\mathrm{mm})\end{array}$ & $\begin{array}{l}\text { Location } \\
\text { error of } \\
\text { FAPSO-I } \\
(\mathrm{mm})\end{array}$ \\
\hline $1-1$ & \multirow{4}{*}{$(392,700,490)$} & $(529,590,501)$ & $(384,719,492)$ & $(383,698,487)$ & $(388,702,489)$ & 176.04 & 20.01 & 9.69 & 4.58 \\
\hline $1-2$ & & $(661,1012,672)$ & $(379,712,516)$ & $(394,694,486)$ & $(386,704,488)$ & 450.37 & 31.45 & 7.46 & 8.25 \\
\hline $1-3$ & & $(682,793,872)$ & $(383,691,495)$ & $(388,698,486)$ & $(389,701,488)$ & 488.54 & 13.67 & 6 & 3.74 \\
\hline $1-4$ & & $(485,936,647)$ & $(380,701,483)$ & $(389,697,485)$ & $(389,702,487)$ & 298.31 & 13.93 & 6.56 & 4.69 \\
\hline $2-1$ & \multirow{4}{*}{$(510,700,410)$} & $(694,918,491)$ & $(512,716,421)$ & $(506,706,408)$ & $(508,702,408)$ & 296.55 & 19.52 & 7.48 & 3.46 \\
\hline $2-2$ & & $(625,625,275)$ & $(520,715,422)$ & $(507,701,412)$ & $(509,701,409)$ & 192.54 & 21.66 & 3.46 & 1.73 \\
\hline $2-3$ & & $(650,768,515)$ & $(513,703,424)$ & $(508,702,406)$ & $(508,699,409)$ & 187.75 & 14.63 & 4.89 & 2.45 \\
\hline $2-4$ & & $(646,895,585)$ & $(510,712,412)$ & $(511,695,405)$ & $(507,701,408)$ & 295.21 & 12.17 & 7.14 & 3.74 \\
\hline $3-1$ & \multirow{4}{*}{$(883,700,690)$} & $(952,1112,763)$ & $(877,706,707)$ & $(887,701,693)$ & $(880,698,688)$ & 424.07 & 19.00 & 5.09 & 4.12 \\
\hline $3-2$ & & $(968,1027,592)$ & $(882,708,702)$ & $(880,695,688)$ & $(881,697,686)$ & 351.79 & 14.45 & 6.16 & 5.39 \\
\hline $3-3$ & & $(799,582,833)$ & $(881,701,703)$ & $(880,696,685)$ & $(880,696,687)$ & 203.54 & 13.19 & 7.07 & 5.83 \\
\hline $3-4$ & & $(785,592,796)$ & $(895,706,693)$ & $(882,700,684)$ & $(881,702,691)$ & 180.29 & 13.75 & 6.08 & 3 \\
\hline
\end{tabular}

Tab. 4. Comparison of laboratory PD source location results among available literature with proposed methods.

\begin{tabular}{|c|c|c|c|c|c|c|c|c|c|}
\hline $\begin{array}{c}\text { PD } \\
\text { source } \\
\text { position } \\
\text { No }\end{array}$ & $\begin{array}{c}\text { Actual } \\
\text { coordinates (mm) }\end{array}$ & $\begin{array}{l}\text { Maximum } \\
\text { deviation } \\
\text { error of LS } \\
\quad(\mathrm{mm})\end{array}$ & $\begin{array}{l}\text { Maximum } \\
\text { deviation } \\
\text { error of } \\
\text { PSO }(\mathrm{mm})\end{array}$ & 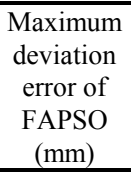 & $\begin{array}{c}\text { Maximum } \\
\text { deviation } \\
\text { error of } \\
\text { FAPSO-I } \\
(\mathrm{mm})\end{array}$ & $\begin{array}{l}\text { Relative } \\
\text { error of } \\
\text { LS (\%) }\end{array}$ & $\begin{array}{l}\text { Relative } \\
\text { error of } \\
\text { PSO (\%) }\end{array}$ & $\begin{array}{c}\text { Relative } \\
\text { error of } \\
\text { FAPSO } \\
(\%)\end{array}$ & $\begin{array}{c}\text { Relative } \\
\text { error of } \\
\text { FAPSO-I } \\
(\%)\end{array}$ \\
\hline $1-1$ & \multirow{4}{*}{$(392,700,490)$} & 200 & 19 & 9 & 4 & 10.03 & 1.14 & 0.55 & 0.26 \\
\hline $1-2$ & & 312 & 26 & 6 & 6 & 25.66 & 1.79 & 0.43 & 0.47 \\
\hline $1-3$ & & 382 & 9 & 4 & 3 & 27.84 & 0.78 & 0.34 & 0.21 \\
\hline $1-4$ & & 236 & 12 & 5 & 3 & 16.99 & 0.79 & 0.37 & 0.27 \\
\hline $2-1$ & \multirow{4}{*}{$(510,700,410)$} & 218 & 16 & 6 & 2 & 16.89 & 1.11 & 0.43 & 0.2 \\
\hline $2-2$ & & 135 & 15 & 3 & 1 & 10.97 & 1.23 & 0.19 & 0.1 \\
\hline $2-3$ & & 140 & 14 & 4 & 2 & 10.69 & 0.84 & 0.28 & 0.14 \\
\hline $2-4$ & & 195 & 12 & 5 & 3 & 16.82 & 0.69 & 0.41 & 0.21 \\
\hline $3-1$ & \multirow{4}{*}{$(883,700,690)$} & 412 & 17 & 4 & 3 & 24.16 & 1.08 & 0.29 & 0.23 \\
\hline $3-2$ & & 327 & 12 & 5 & 4 & 20.05 & 0.82 & 0.35 & 0.31 \\
\hline $3-3$ & & 143 & 13 & 5 & 4 & 11.59 & 0.75 & 0.40 & 0.33 \\
\hline $3-4$ & & 108 & 12 & 6 & 2 & 10.27 & 0.78 & 0.35 & 0.17 \\
\hline
\end{tabular}

Tab. 5. Error analysis comparison of laboratory PD source among available literature with the proposed methods.

method is more superior in terms of minimum location error and maximum deviation error for the accurate PD source localization in giving global best solution in comparison to FAPSO, LS, PSO, SA, LPSO, QGA and GA.

Finally, this proposed method has shown good implementation and appropriateness for localization of PD source and the output results of the proposed method when compared to other methods reported in the literature attained desired better results. In future this FAPSO method can also be applied to radars and channel estimation areas for evaluating better results when compared to iterative and optimization methods.

\section{References}

[1] HOWELLS, E., NORTON, E. T. Location of partial discharge sites in on-line transformers. IEEE Transactions on Power
Apparatus and Systems, 1981, vol. 100, no. 1, p. 158-161. DOI: 10.1109/TPAS.1981.316872

[2] LUNDGAARD, L. E. Partial discharge XIII. Acoustic partial discharge detection fundamental considerations. IEEE Electric Insulation Magazine, 1992, vol. 8, no. 4, p. 25-31. DOI: 10.1109/57.145095

[3] LUNDGAARD, L. E. Partial discharge XIV: Acoustic partial discharge detection - practical application. IEEE Electrical Insulation Magazine, 1995, vol. 8, no. 5, p. 34-43. DOI: $10.1109 / 57.156943$

[4] ELEFTHERION, P. M. Partial discharge XXI: Acoustic emissionbased $\mathrm{PD}$ source location in transformer. IEEE Electrical Insulation Magazine, 1995, vol. 11, no. 6, p. 22-26. DOI: $10.1109 / 57.475905$

[5] LU, Y., TAN, X., HU, X. PD detection and localization by acoustic measurement in an oil-filled transformer. IEE Proc Science Measurement Technology, 2000, vol. 147, no. 2, p. 81-85. DOI: 10.1049/ip-smt: 20000223

[6] IEEE STD. C57.127-2007. IEEE guide for the detection and location of acoustic emissions from partial discharges in oil- 
immersed power transformers and reactors. DOI: 10.1109/IEEESTD.2007.4293265

[7] MARKALOUS, S. M., TENBOHLEN, S., FESER, K. New robus non-iterative algorithms for acoustic PD-localization in oil/paperinsulated transformers. In 14th International Symposium on High Voltage Engineering. Beijing (China), 2005, p. 1-6.

[8] MARKALOUS, S. M., TENBOHLEN, S., FESER, K. Detection and location of partial discharges in power transformers using acoustic and electromagnetic signal. IEEE Transaction on Dielectrics and Electrical Insulation, 2008, vol. 15, no. 6, p. 1576-1583. DOI: 10.1109/TDEI.2008.4712660

[9] VELOSO, G. F. C., BORGES DA SILVA, L. E., LAMBERTTORRES, G., et al. Localization of partial discharges in transformers by the analysis of the acoustic emission. In IEEE International Symposium on Industrial Electronics. Montreal (Quebec, Canada), 2006. p. 537-541. DOI: 10.1109/ISIE.2006.295515

[10] VELOSO, G. F. C., BORGES DA SILVA, L. E., LAMBERTTORRES, G., et al. A strategy to locate partial discharges in power transformers using acoustic emission. In International Conference on Renewable Energies and Power Quality (ICREPQ 2007). Seville (Spain), 2007. DOI: 10.13140/RG.2.1.2181.4001

[11] TANG, L., LUO, R., DENG, M., SU, J. Study of partial discharge localization using ultrasonic in power transformer based on particle swarm optimization. IEEE Transaction on Dielectrics and Electrical Insulation, 2008, vol. 15, no. 2, p. 492-495. DOI: 10.1109/TDEI.2008.4483469

[12] KUNDU, P., KISHORE, N. K., SINHA, A. K. A non-iterative partial discharge source location method for transformers employing acoustic emission technique. Applied Acoustics, 2009, vol. 70 , no. $11-12$, p. 1378-1383. DOI 10.1016/j.apacoust.2009.07.001

[13] KIL, G. S., KIM, I. K., PARK, D. W., et al. Measurements and analysis of the acoustic signals produced by partial discharges in insulation oil. Current Applied Physics, 2009, vol. 9, no. 2, p. 296-300. DOI: 10.1016/j.cap.2008.01.018

[14] KUO, C. C. Artificial recognition system for defective types of transformers by acoustic emission. Expert Systems Applications, 2009, vol. 36, no. 7, p. 10304-10311. DOI: 10.1016/j.eswa.2009.01.046

[15] BOCZAR, T., BORUCKI, S., CICHOD, A., et al. Application possibilities of artificial neural networks for recognizing partial discharges measured by the acoustic emission method. IEEE Transaction on Dielectrics and Electrical Insulation, 2009, vol. 16, no. 1, p. 214-223. DOI: 10.1109/TDEI.2009.4784570

[16] LIU, H. L., LIU, H. D. Partial discharge localization in power transformers based on the sequential quadratic programminggenetic algorithm adopting acoustic emission techniques. European Physics Journal Applied Physics, 2014, vol. 68, no. 1, p. 1-16. DOI: $10.1051 /$ epjap /2014140318

[17] LIU, H. L. Acoustic partial discharge localization methodology in power transformers employing the quantum genetic algorithm. Applied Acoustics, 2016, vol. 102, p. 71-78. DOI: 10.1016/j.apacoust.2015.08.011

[18] HASIRCI, Z., CAVDAR, I. H., OZTURK, M. Modelling and link performance analysis of bus bar distribution systems for narrowband PLC. Radioengineering, 2017, vol. 26, no. 2, p. 611-620. DOI: $10.13164 / \mathrm{re} .2017 .0611$

[19] HAN, C., WANG, L. Array pattern synthesis using a digital position shift method. Radioengineering, 2016, vol. 25, no. 3 , p. 573-580. DOI: $10.13164 /$ re.2016.0573

[20] TAGCU, E, KAYA, I., YAZCAN, A. CMF-DFE based adaptive blind equalization using particle swarm optimization.
Radioengineering, 2016, vol. 25, no. 1, p. 124-131. DOI: $10.13164 / \mathrm{re} .2016 .0124$

[21] SONG, L., LIANG, M., JI, H. Box-particle implementation and comparison of cardinalized probability hypothesis density filter. Radioengineering, 2016, vol. 25, no. 1, p. 177-186. DOI: $10.13164 /$ re.2016.0177

[22] GUNES, F., DEMIREL, S., MAHOUTI, P. Design of a front-end amplifier for the maximum power delivery and required noise by HBMO with support vector micro strip model. Radioengineering, 2014, vol. 23, no. 1, p. 134-143. ISSN: 1210-2512

[23] CAKIR, O., KAYA, H., YAZGAN, A., et al. Emitter location finding using particle swarm optimization. Radioengineering, 2014, vol. 23, no. 1, p. 252-258. ISSN: 1210-2512

[24] ABDUL RANI, K. N., ABD MALEK, M. F., SIEW CHIN, N. Nature-inspired cuckoo search algorithm for side lobe suppression in a symmetric linear antenna array. Radioengineering, 2012, vol. 21 , no. 3, p. 865-874. ISSN: 1210-2512

[25] ADIGUZEL, T., AKBULET, A., YILMAZ, A. E. Estimation of time-varying channel state transition probabilities for cognitive radio systems by means of particle swarm optimization. Radioengineering, 2012, vol. 21, no. 1, p. 104-109. ISSN: 1210-2512

[26] ZHONGKUN MA, VAN DEN BOSCH, G. A. E. Comparison of weighted sum fitness functions for PSO optimization of wideband medium-gain antennas. Radioengineering, 2012, vol. 21, no. 1, p. 504-511. ISSN: 1210-2512

[27] SEDENKA, V., RAIDA, Z. Critical comparison of multi-objective optimization methods: Genetic algorithms versus swarm intelligence. Radioengineering, 2010, vol. 19, no. 3, p. 369-377. ISSN: $1210-2512$

[28] LACIK, J., LAGER, I. E., Z., RAIDA, Z. Multi criteria optimization of antennas in time domain. Radioengineering, 2010, vol. 19 , no. 1, p. 105-110. ISSN: 1210-2512

[29] RAPTIS, V., TATIS, G., CHRONOPOULOS, S. K., et al. Development and experimental measurements of a tunable antenna. Communications and Network, 2013, vol. 5, no. 3, p. 220-224. DOI: $10.4236 / \mathrm{cn} .2013 .53026$

[30] KRACEK, J., MAZANEK, M. Wireless power transmission for power supply: State of art. Radioengineering, 2011, vol. 20, no. 2, p. 457-463. ISSN: $1210-2512$

[31] KADLEC, P., KEJIK, P., RAIDA, Z. Comparison of pilot symbol embedded channel estimation algorithms. Radioengineering, 2009, vol. 18 , no. 4, p. 485-490. ISSN: 1210-2512

[32] CHRONOPOULOS, S. K., CHRISTOFILAKIS, V., TATSIS, G., et al. Performance of turbo coded OFDM under the presence of various noise types. Wireless Personal Communication, 2016, vol. 87, p. 1319--1336. DOI: 10.1007/s 11277-015-3055-1

[33] YANG XIN-SHE. Nature-Inspired Metaheuristic Algorithms. $2^{\text {nd }}$ ed. United Kingdom, L University Press, 2010. ISBN: 9781905986286

[34] BAJPAI, P., SINGH, S. N. Fuzzy adaptive particle swarm optimization for bidding strategy in uniform price spot market. IEEE Transactions on Power Systems, 2007, vol. 22, no. 4, p. 2152-2160. DOI: 10.1109/TPWRS.2007.907445

\section{About the Authors ...}

Kalyan Chakravarthi MEKA is currently a Ph.D. student in the Department of Electrical Engineering, NIT Warangal. He received his M Tech from AN University in 
2010. His research interests include condition monitoring on power transformers.

GIRIDHAR A V received his doctorate degree from the Indian Institute of Technology, Madras in 2011. He joined the National Institute of Technology, Warangal, India in 2012. Presently, he is an Assistant Professor in the Department of Electrical Engineering. His research area includes high voltage engineering, condition monitoring and diagnosis of high voltage power apparatus.
SIVA SARMA D V S S received his B. Tech. in EEE and M.Tech. in Power Systems from JNTU College of Engineering, Anantapur in 1986 and 1988, respectively. He received his doctorate degree from the Indian Institute of Technology, Madras in 1993. He joined the National Institute of Technology, Warangal, India in 1992. Presently, he is a Professor in the Department of Electrical Engineering. His areas of interest include power system transients, power quality, protection and condition monitoring of power apparatus and EMTP applications. 